1. BDS,

FCPS (Oral \& Maxillofacial Surgery) Assistant Professor Oral \&

Maxillofacial Surgery

Sir Syed College of Medical

Sciences for Girls.

2. BDS,

FCPS (Oral \& Maxillofacial Surgery)

Assistant Professor-Oral \&

Maxillofacial Surgery

Dental College-HITEC Institute of

Medical Sciences-Taxilla Cantt.

3. BDS, MSc (Endodontics)

4. BDS,

FCPS (Oral \& Maxillofacial Surgery)

Assistant Professor Oral \&

Maxillofacial Surgery

Wah Medical College, Wah Cantt.

5. BDS, MDS, Ph.D (Periodontology)

Associate Professor and HOD-

Periodontology

Sir Syed College of Medical

Sciences for Girls.

6. BDS, FCPS (Orthodontics)

Assosiate Professor,

HOD Orthodontics

Saidu College of Dentistry.

Correspondence Address:

Dr. Maimoona Siddiq

Department of Oral \& Maxillofacial

Surgery

Dental College-HITEC Institute of

Medical Sciences

Taxilla Cantt.

the_dentist007@hotmail.com

Article received on:

20/11/2020

Accepted for publication:

$13 / 03 / 2021$

\section{Pattern of isolated mandibular symphysis fracture and trends in management at a tertiary care hospital of Karachi, Pakistan.}

\begin{abstract}
Junaid Shakeel' ${ }^{1}$, Maimoona Siddiq², Sumaira Rafique ${ }^{3}$, Usman ul Haq ${ }^{4}$, Yousuf Moosa ${ }^{5}$, Erum Behroz
ABSTRACT... Objective: To find the pattern of isolated mandibular symphysis fracture and trends in management at a tertiary care hospital of Karachi, Pakistan. Study Design: Crossectional study. Setting: Department of Oral Surgery, Sir Syed Medical \& Dental HospitalKarachi, Pakistan. Period: January 2018 to December 2019. Material \& Methods: Eighty one patients were selected on the basis of inclusion and exclusion criteria. They were diagnosed with isolated anterior mandibular fracture on basis of detailed history, thorough clinical examination and a radiologic investigation (OPG). Etiology of fracture and gender distribution was observed, fracture pattern was observed on basis of helmet wearing. Results: There was a male predilection with a male to female ratio of 4.3:1. Road traffic accident was the commonest cause. $82.7 \%$ of patients were not wearing helmet at time of incidence and $69 \%$ from all patients had displaced mandibular fracture which resulted in derranged occlusion. Conclusion: Isolated anterior mandibular fractures is common in younger age group, with a male predilection. Most common etiologic factor is road traffic accident. Displaced fracture pattern is prevalent among patients who were not wearing helmet at time of incidence.
\end{abstract}

Key words: Helmet, Maxillofacial Trauma, Mandibular Symphysis, Occlusion, Titanium Bone Plates.

Article Citation: Shakeel J, Siddiq M, Rafique S, Usman ul Haq, Moosa Y, Behroz E. Pattern of Isolated Mandibular Symphysis Fracture and trends in management at a tertiary care hospital of Karachi, Pakistan. Professional Med J 2021; 28(12):1778-1782. https://doi.org/10.29309/TPMJ/2021.28.12.6224

\section{INTRODUCTION}

Mandible is the only mobile bone of face which makes it vulnerable to fracture. ${ }^{1}$ It is second most common facial bone, after nasal bone, to get fractured. ${ }^{2}$ Areas of weakness in the mandible are mental foramen, condyle and mandibular angle. ${ }^{1}$ Fracture of the mandible accounts for $36 \%$ to $59 \%$ out of all maxillofacial trauma. ${ }^{4}$ It is a $\mathrm{U}$ shaped bone which is connected to rest of the facial skeleton via a pair of temporomandibular joints. Mandible can be anatomically divided into various regions. These includes; symphysis, para-symphysis, body, angle and ramus areas. ${ }^{3}$

Anterior mandible fractures include symphysis(midline) and parasyphysis(lateral to central incisor tooth and medial to bicuspids). ${ }^{5}$ Approximately $17 \%$ of all the mandibular fractures are anterior mandibular fractures. ${ }^{5}$ The most common etiologies of facial fractures are road traffic accidents, fall, interpersonal violence, sport injuries, fire arm injuries and industrial trauma. ${ }^{6}$ Motor vehicle accident is usually associated with head, chest, abdominal and orthopaedic injuries. ${ }^{4}$ Road traffic accidents remain the most common cause of mandibular fracture in many countries, This probably is due to the lack of proper legislation for passenger safety measures. Higher incidence of facial and neurological injuries has been observed in patients who were not wearing helmet at the time of incidence.

$70 \%$ to $80 \%$ of mandibular fractures occur in males and the mean age range is 20 to 30 years while lowest incidence of mandibular fractures is seen in age groups above 70 years and below 5 years. ${ }^{4}$ 
Mandibular fractures are required to be reduced and fixed because mandible plays primary role in deglutition, speech, swallowing and appearance. ${ }^{4}$ Over the time, the treatment approach towards anterior mandibular fractures has evolved from closed reduction and external fixation to open reduction internal fixation. ${ }^{3,4}$ Closed reduction and external fixation can be performed via intermaxillary fixation using eyelets or arch bars. ${ }^{4} \mathrm{Open}$ reduction and internal fixation can be achieved by using 2 miniplates and monocrotical screws or lag screws. ${ }^{4}$ mini plates are applied along champy's lines of osteosynthesis. One plate is applied $5 \mathrm{~mm}-10 \mathrm{~mm}$ below the root apices of teeth; the tension zone, The other plate is applied at the inferior border of mandible; compression zone.

The fractures of anterior mandibular region (symphysis and parasymphysis) are inherently unstable. They do not have two of the stabilizing factors provided to fractures of the posterior tooth-bearing mandible: the interdigitated cusps and fossae of bicuspid and molar teeth and the supporting effects of the masseter and internal pterygoid muscles, which form a natural sling. ${ }^{4}$ Moreover they are associated with torsional forces produced by suprahyoid muscles.

Anterior mandible fractures are mostly associated with bilateral condylar fracture due to impact of force distribution, Thus improper management may lead to Temporomandibular joint ankyloses which is a debilitating complication of condylar fractures, mostly observed in children. ${ }^{4}$

The most significant indication for surgical exploration of fracture is occlusion. ${ }^{4} \mathrm{~A}$ derranged occlusion also indicate displaced fracture pattern , it can manifest as crossbite, open bite or deep bite. ${ }^{4}$ Mandibular fractures are diagnosed with the help of a thorough history, intra-oral and extraoral clinical examination ${ }^{6-10}$ and radiographic investigations (OPG). ${ }^{11,12}$

Other imaging modalities includes PA face, Lateral Oblique and CT scan. All investigations have their own indications and applications which must be weighed by the treating surgeon, before opting for any one of the investigations. In this study, radiograph of choice was Orthopantomogram (OPG), which is easily available, cost effective and provides most valuable information in a single radiograph.

Rationale of this study was to observe the pattern of isolated mandibular symphysis fracture in terms of displaced/undisplaced fracture and its relation with helmet wearing at time of trauma, this can help in legislation for helmet wearing, and prevention from severely displaced/complex mandible fractures which are more debilitating , challenging to treat, include prolonged hospital stay, and an increased financial burden also.

\section{MATERIAL \& METHODS}

Based on the inclusion and exclusion criteria, Random patients who reported in the out patient department(OPD) of Oral and Maxillofacial Surgery Department, Sir Syed Medical \& Dental Hospital-Karachi were selected, Twenty-four months crossectional study was conducted, from $1^{\text {st }}$ January 2018 to $31^{\text {st }}$ December 2019. The inclusion criteria followed in the study encompassed; Isolated mandibular symphysis fractures only, confirmed on a pre-operative radiograph and clinical examination. Patients from both genders between age range of 20 years to 60 years were considered in study. Fracture with clinically derranged occlusion was considered as "displaced" while "undisplaced" fractures were those with intact occlusion, Patients excluded from this study were those with Medically compromised states ie diabetics, chronic illness, tumour patients, patients with chronic renal failure, syndromes which involve facial skeleton, comminuted fractures(confirmed on a pre operative radiograph), fracture mandible(symphysis) associated with other facial fractures and Edentulous patients were also excluded from data.

After obtaining institutional ethical approval letter on $29^{\text {th }}$ December 2017 with letter Number: F.8/2017/EAL/DC/SSH, Informed consent was obtained from all the subjects. Following the selection criteria, a number of 81 patients were selected. A detailed history was acquired from 
every patient, comprising of age, gender, cause of trauma, presenting complain, history of presenting complain, systemic review, past medical history and helmet was worn at time of incidence or not, history of drugs abuse/alcoholism was taken. A thorough clinical examination was conducted and findings were noted down on profroma(specially designed for the study). These clinical findings were correlated with radiological investigations. open reduction and internal fixation was done in all subjects. SPSS version 26 was used for data analysis, patients were observed on basis of gender distribution, age, etiology of fracture, pattern of fracture(displaced/undisplaced) and wearing of helmet at time of incidence(yes/no).

$\mathrm{P}=0.05$ was considered significant, Chi-square was applied to analyse qualitative variables like fracture pattern and helmet worn, t-test is applied for age and gender distribution.

\section{RESULTS}

There were a total of 81 patients with isolated mandibular symphysis fractures comprising of 65 male patients and 16 female patients with a male to female ratio of 4.31:1 (Figure-1), mean age of males and females was 36 and 34 years respectively. Sig value $=0.3$ from independent t-test is found among gender distribution (males and females) and age of patietns, which is not significant statistically. (Table-I)

The most common etiologic factor was road traffic accident with 58 number of patients $(71.6 \%)$, Fall was the etiology in 15 patients(18.5\%), assault in 3 patients $(3.7 \%)$, sports injuries in only 5 patients (6\%). (Figure-2)

\begin{tabular}{|l|c|c|c|c|}
\hline Gender & N & Mean Age & Std. Deviation & P-Value \\
\hline Male & 65 & 36.4154 & 10.66814 & 0.3 \\
\hline Female & 16 & 34.6250 & 12.98140 & \\
\hline \multicolumn{4}{|c}{ Table-I. Age \& gender distribution. } \\
\hline
\end{tabular}

Fracture pattern shows $69.1 \%$ were displaced fractures and $30.9 \%$ as undisplaced, along with the fact that only $17.3 \%$ of patients were wearing helmet at time of incidence and $82.7 \%$ were not wearing helmet. (Table-II, Table-III).

\begin{tabular}{|c|c|}
\hline & Frequency (\%) \\
\hline Displaced & $56(69.1 \%)$ \\
\hline Undispalced & 25 (30.9\%) \\
\hline Total & $81(100.0 \%)$ \\
\hline \multicolumn{2}{|c|}{ Table-II. Fracture pattern. } \\
\hline & Frequency (\%) \\
\hline Yes & $14(17.3 \%)$ \\
\hline No & $67(82.7 \%)$ \\
\hline Total & $81(100.0 \%)$ \\
\hline
\end{tabular}

Table-IV shows, P value less than .001 from chisquare test which indicate statistically significant relation between fracture pattern(displaced/ undisplaced) and helmet worn at time of incidence. Among 67 subjects (not wearing helmet) $82.1 \%$ had displaced fracuture pattern and $17.9 \%$ had undisplaced pattern, and 14 subjects(wearing helmet) had $92.9 \%$ incidence of undisplaced fracture while $7.1 \%$ subjects had displaced fracture pattern.

Thus it is evident that displaced fracture pattern is prevalent among patients who were not wearing helmet at the time of incidence. None of the patient had history of drug abuse/alcoholism.

\begin{tabular}{|c|c|c|c|}
\hline \multicolumn{2}{|c|}{ Wearing Helmet (N=14) } & \multicolumn{2}{|c|}{$\begin{array}{c}\text { Not Wearing Helmet } \\
(\mathbf{N}=67)\end{array}$} \\
\hline Displaced & Undisplaced & Displaced & Undisplaced \\
\hline $\mathrm{n}=01$ & $\mathrm{n}=13$ & $\mathrm{n}=55$ & $\mathrm{n}=12$ \\
$7.1 \%$ & $92.9 \%$ & $82.1 \%$ & $17.9 \%$ \\
\hline \multicolumn{4}{|r|}{$\mathbf{P}=\mathbf{0 . 0 0}$} \\
\hline
\end{tabular}

Table-IV. Relation of Helmet (wearing/notwearing) with fracture pattern (displaced/undisplaced)

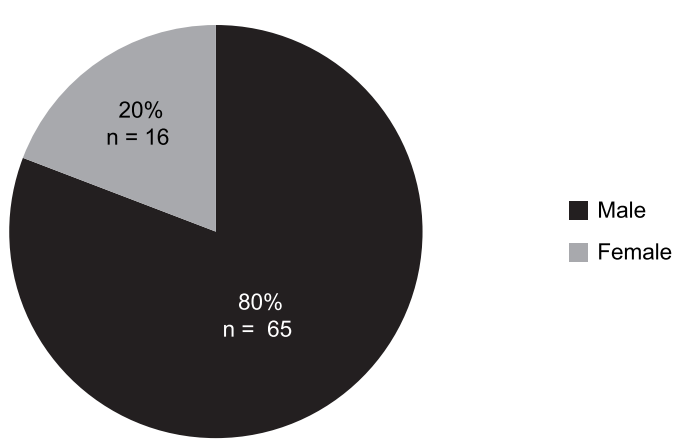

Figure-1. Gender distribution. 


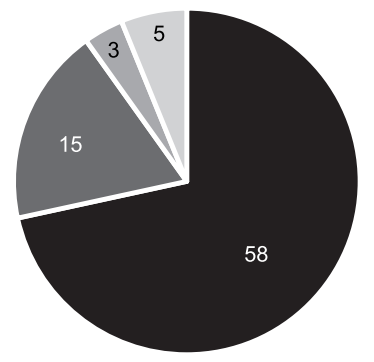

$\square$ road traffic accident $\square$ fall $\square$ interpersonal violance $\square$ sports

Figure-2. Etiology of fracture.

\section{DISCUSSION}

This study was undertaken with the view to review the prevelance and pattern of isolated anterior mandibular fractures in local population of Karachi.

In this study, mean age is 36 years and 34 years for males and females respectively, These findings correspond to Shapiro et $\mathrm{al}^{13}$ who reported mean age to be 34.1 years. This study reveals a male predilection $(80 \%)$ in the fractures of anterior mandible, this finding is in correlation with the study conducted by John Koshy et al. ${ }^{4}$ Other studies such as those conducted by Kamali $U$ et $\mathrm{al}^{11}$ and Holt $R G$ et $a{ }^{9}$ also concluded that males are more effected as compared to females. Method of treatment for mandibular fractures varies from closed reduction and external fixation to open reduction and internal fixation. Methods of internal fixation varies from miniplate fixation to lag screws. Al Moraissi et $\mathrm{al}^{7}$ and John C Koshy et $\mathrm{al}^{4}$ reported various methods of mandibular fixation. Although open reduction and internal fixation remains the gold standard.

Our study revealed that the commonest etiologic factor for mandibular fractures is road traffic accident. This finding correlates with the studies by Haung $\mathrm{RH}^{10}$ et al, Holt RG et $\left.\mathrm{a}\right|^{9}$ and Luce et al. ${ }^{14}$ Shah et $a{ }^{15}$, Ahmed et $\mathrm{al}^{16}$ and King et $\mathrm{al}^{8}$ reported assault as the main cause, this is contradictory to the findings of our study. The treatment options varies from external fixation to internal fixation. ${ }^{17,18}$ In this study, all the patients were treated with open reduction and internal fixation method and post operative results were satisfactory with regain of occlusion and fracture healing.

Displaced fracture pattern was prevalent among those who were not wearing helmet at time of incidence, which clearly indicates that road safety precautions and helmet wearing is affective in reducing and preventing the incidence of high energy trauma. Usha et $\mathrm{al}^{19}$ observed an immense reduction in maxillofacial trauma patients when they observed pre-law and post-law data, after implementing the "mandatory helmet law" in 2007 in kerala.

To observe "Isolated Symphysis Fracture" only, is a limitation of this study, patients with multiple fractures of mandible are mostly reporting in "Emergeny Department", Our limitation was to include patients reporting in OPD only. More over, alteast two plain radiographs or a CT scan face is required in case of multiple mandible or facial fractures which was an other limitation of study, as financial constraints didnot allowed us to advice OPD pateints for multiple radiographs.

\section{CONCLUSION}

Isolated anterior mandibular fractures is prevelant in younger age patients, with a male predilection. Most common etiologic factor is road traffic accident. Helmet wearing is a prodent way to avoid high energy impact which cause displaced fracture pattern. Open reduction and internal fixation is an effective method of mandibular fixation.

Copyright $\odot 13$ Mar, 2021.

\section{REFERENCES}

1. Natu SS, Pradhan H, Gupta H, et al. An epidemiological study on pattern and incidence of mandibular fractures. Plast Surg Int. 2012; 2012:1-7.

2. Ashraf N, Khan M, et al. Pattern of mandibular fractures resulting from fall. Pak Oral Dent J. 2014;34(2):245248.

3. Noreen R, Khan M. Characteristics of symphysis and parasymphysis mandibular fractures. Pak Oral Dent J. 2014; 34(1):46-49. 
4. Koshy JC, Feldman EM, Chike-Obi CJ, Bullocks JM. Pearls of mandibular trauma management. Semin in plast Surg. 2010; 24(4):357-374.

5. Jin KS, Lee $\mathrm{H}$, Sohn JB, et al. Fracture patterns and causes in the craniofacial region: An 8-year review of 2076 patients. Maxillofac Plast Reconstr Surg. 2018; 40(1):1-11.

6. Yuen HW, Hohman MH, Mazzoni T. Mandible Fracture. Stat Pearls. 2020;1-4.

7. Al-Moraissi EA, Ellis E. Surgical management of anterior mandibular fractures: A systemic review and meta-analysis. J Oral Maxillofac Surg. 2014; 72(12):2507-2511.

8. King RE, Scianna JM, Petruzzelli GJ. Mandible fracture patterns: A suburban trauma center experience. Am. J. Otolaryngol. 2004; 25(5):301-7.

9. Holt RG, Maxillofacial trauma. In: Otolaryngology head and neck surgery. Mosby Company. 1986; 19:314-4.

10. Haug RH, Prather J, Indresano AT. An epidemiologic survey of facial fractures and concomitant injuries. J Oral Maxillofac Surg. 1990; 48(9):926-932.

11. Kamali U, Pohchi A. Mandible fracture at HUSM: A 5 year retrospective study. Arch Orofac. Sci. 2009; 4(2): 33-5.
12. Ghodke MH, Bhoyar SC, Shah SV. Prevalence of mandibular fractures reported at C.S.M.S.S Dental College, aurangabad from february 2008 to september 2009. J Int Soc Prev Community Dent. 2013; 3(2):51-58.

13. Shapiro AJ, Johnson RM, Miller SF, McCarthy MC. Facial fractures in a level I trauma centre: The importance of protective devices and alcohol abuse. Injury. 2001; 32(5):353-6.

14. Luce EA, Tubb TD, Moore AM. Review of 1,000 major facial fractures and associated injuries. Plast. Reconstr. Surg. 1979; 63(1):26-30.

15. Shah A.S, Shah A.A, Salam A. Pattern and managementof mandibular fractures: A study conducted on 264 patients. Pak Oral Dent J. 2007; 27(1):103-106.

16. Al Ahmed HE, Jaber MA, Fanas SH, Karas M. The pattern of maxillofacial fractures in Sharjah, United Arab Emirates: A review of $\mathbf{2 3 0}$ cases. Oral Surg Oral Med Oral Pathol Oral Radiol Endod. 2004; 98(2):166-70.

17. Brown JS, Grew N, Taylor C, Millar BG: Intermaxillary fixationcompared to miniplateosteosynthesis in the management offractured mandible: $\mathrm{An}$ audit. $\mathrm{Br} \mathrm{J}$ Oral Maxillofac Surg. 1991; 29(5):308-311.

18. Cawood Jl: Small plate osteosynthesis of mandibular fractures. Br J Oral Surg. 1985; 23(2):77-91.

19. Usha M, Ravindran V, Soumithran CS, et al. The impact of mandatory helmet law on the outcome of maxillo facial trauma: A comparative study in kerala. J Maxillofac Oral Surg. 2014 Jun; 13(2):176-83.

\begin{tabular}{|c|c|c|c|}
\hline \multicolumn{4}{|c|}{ AUTHORSHIP AND CONTRIBUTION DECLARATION } \\
\hline No. & Author(s) Full Name & Contribution to the paper & Author(s) Signature \\
\hline 1 & Junaid Shakeel & Author & \\
\hline 2 & Maimoona Siddiq & Author & \\
\hline 3 & Sumaira Rafique & Co-Author & \\
\hline 4 & Usman ul Haq & Co-Author & \\
\hline 5 & Yousuf Moosa & Co-Author & \\
\hline 6 & Erum Behroz & Co-Author & $\zeta_{w=}=\ldots$ \\
\hline
\end{tabular}

